\title{
The impact of global change - the COVID-19 pandemic on the evaluation of employee performance in companies in the Czech Republic
}

\author{
Šárka Čemerková, ${ }^{1,}$, Pavla Pokorná $^{1}$, and Vojtěch Malátek ${ }^{1}$ \\ ${ }^{1}$ Silesian University in Opava, School of Business Administration in Karvina, Univerzitní náměstí \\ 1934/3, 73340 Karviná, Czech Republic
}

\begin{abstract}
Research background: Human resource management is a process that includes several consecutive phases. Employee performance evaluation is one of them. It is a starting point for rewarding employees as well as for several other personnel activities, such as personnel planning, job analysis, employee deployment, and more. The company may approach the evaluation of employee performance itself in different ways. Employee performance can be evaluated in different ways and with different frequencies. The setting up of the employee performance evaluation system is based on global and local conditions, corporate culture, and the needs of the company's management.

Purpose of the article: The article aims discuss the approach of the companies in the Czech Republic to the evaluation of employee performance and to evaluate whether or not there have been any changes in this system due to the global pandemic COVID-19.

Methods: The starting point of our research is quantitative data on companies in the Czech Republic, obtained by a questionnaire survey immediately before the COVID-19 pandemic and after its first year. Using the chi-square test the attitudes of these companies to the evaluation of employee performance and their changes as a result of COVID-19 are evaluated.

Findings \& Value added: Conclusions are drawn regarding changes in the system of employee performance evaluation, the method of implementation and frequency of evaluation, and its use in personnel work in the first year of the COVID-19 pandemic.
\end{abstract}

Keywords: COVID-19; Czech Republic; employee performance evaluation; HRM; research

JEL Classification: $L 21 ; L 23 ; M 12$

* Corresponding author: cemerkova@opf.slu.cz 


\section{Introduction}

Few single epidemics have a serious and lasting impact on the world economy, global health, and human life as a whole. However, in the case of COVID-19, the world is expected to face a severe recession even if the spread of the virus is controlled (Wei et al., 2021). The global pandemic COVID-19 has affected society-wide development on a large scale, not excluding the Czech Republic. Among the most extensive impacts we can mention the individual lives of citizens, but also companies that are engaged in production, trade, services, and other activities that ensure the existence and development of society. It follows that the COVID19 pandemic has broad-based implications for the world economy, and thus global society. The COVID-19 pandemic has adversely affected the lives of people around the world in millions of ways. Due to this severe epidemic, all countries in the world have been affected by all aspects, mainly economic (Wei et al., 2021). Therefore, it turns out that it will be very necessary to deal especially with the economic effects of COVID on employees.

This pandemic has had many serious consequences for the activities of companies all over the world, including the Czech Republic. Across the world and European companies, partial and full lockdowns were announced, companies had to cease many economic activities, and extend the halted production restart date (Lee et al., 2021). As a result, this meant the gradual reduction or closure of entire industries, services, trade, and transport. Essentially, each of us has experienced the effects of disrupting logistics chains. This pandemic has brought new challenges in the form of the need to deal with situations such as the complete cessation of production to the need for new recruitment, sourcing, and hiring.

The pandemic has forced many companies to change their business activities, which in turn leads to the need to recruit and hire new employees who will be able to perform as expected. For this reason, too, the evaluation of the work performance of employees is proving to be one of the key personnel tasks of most companies.

Due to the COVID-19 pandemic, the relationship between employers and employees has changed significantly. Literally, employment conditions have changed overnight. On the one hand, the economic conditions of work organization have changed, which manifested itself, for example, in the need to change the portfolio of business activities, and on the other hand, it places high demands on professionalism and performance of employees, which often become the sole criterion when selecting specialists (Mihus et al., 2021).

To function as a fully valued workforce, an employee must constantly broaden his abilities, knowledge, and skills (Stofkova and Sukalova, 2020). This puts pressure on the development of his work skills and his ability to flexibly adapt to changing conditions. The evaluation of his work performance will then prove the extent to which he met the expectations of the employer. In this context, the article deals with the issue of evaluating the performance of employees in terms of changes brought about by the COVID-19 pandemic in the conditions of companies in the Czech Republic.

\section{Theoretical background}

The COVID-19 pandemic has affected the whole world without significant differences. It has changed the traditional relationships between employers, employees, and the working systems. Some aspects, such as workplace health and safety, workplace flexibility, and other working conditions, are receiving increased attention. These factors as well as other job design factors responsible to create real value for employers and improve their performance (Aldogan et al., 2021).

Nowadays a global world is characterized by constant changes in society, technical development, legislation, and the economy (Stofkova and Sukalova, 2020). However, the ability to respond to the ongoing changes caused by the COVID-19 pandemic requires the 
use of a wide range of innovations, quality management of production processes and input sources, their coordination, planning, and organization. However, all this would not be possible without one important factor - human capital (Tomcikova and Coculova, 2020). In a world of globalization, Big Data, the Internet of Things, and advances in technology, their employees are fundamental and the main differences between organizations (Governer and Bussin, 2020).

Human capital, as an important production factor, requires a thoughtful approach on the part of management. Human capital management thus represents a modern concept of people management, which in turn leads to an increase in the performance and competitiveness of the company within the context of sustainability (Kucharčíková, 2018).

The concept of employee performance is approached by different authors from different angles, and there is no universal definition of this concept. This is a very interesting topic in the field of industrial and organizational psychology (Aşkun et al., 2021). For example, Purnaya et al. (2016) state that the employee's performance is the result of the work he has achieved in performing the tasks assigned to him, based on skills, experience, sincerity, and time. These authors say that employee performance can be interpreted as the level at which employees meet job requirements. The term performance comes from the word job performance or actual performance (work performance or actual achievement achieved by someone), or also the work quality and quantity to be achieved by an employee in carrying out their duties in accordance with the responsibilities given to him (Mangkunegara cited in Humato and Melinda, 2021). Performance means the work of an employee on his work in quality and quantity according to the time determined to achieve organizational goals (Humato and Melinda, 2021).

According to Agarwal and Farndale (2017), many factors influence an employee's performance, which they understand as a function of the employee's ability and motivation to produce effectively and contribute to business goals. Erlina (2020) also agrees with the influence of a whole range of factors. These factors may be psychological, sociological, anthropological, demographic, and similar (Aşkun et al., 2021). In terms of business, there are different types of compensation, benefits, health care, safety, and working conditions (Aldogan et al., 2021). These factors also include the influences caused by the global pandemic COVID-19. That is why this issue is given special attention in research surveys around the world. In the next part, this article presents the results of our investigation of the impacts of COVID-19 on the evaluation of employee performance in companies in the Czech Republic.

Companies conduct performance evaluations based on the idea that there must be an objective evaluation system in the organization Munandar (2015). The practical conditions in individual companies significantly determine the method and system of conducting employee evaluations. Traditions, company culture, results of communication between management and employees, and other factors also go into it. Therefore, we do not encounter uniform performance evaluation systems. However, there is agreement on the importance of carrying out the evaluation. By evaluating performance, top managers can obtain an objective basis for providing compensation for the quantity and quality of work performed, which has contributed to the development of society as a whole. All of this is expected to create motivation and stimulation for each workgroup in the company to work more efficiently and effectively (Humato and Melinda, 2021).

Performance evaluation should be based on the company's personnel strategy, which aims to contribute to the achievement of company-wide goals. The basic tool from the point of view of the company's management is therefore the management of employee performance. Performance management is a key personnel process. From this perspective, performance management should pay special attention. The employees themselves have different attitudes towards the process of managing their performance. One of the process's regularities and 
objectivity is viewed positively by some employees, but others see it as a subjective orientation of managers that does not contribute to their performance. One important way to improve the performance management process is to focus on supporting employee involvement as a driver of higher performance (Gruman and Saks, 2011). In practical conditions, there are implementations of a number of different models of the performance management process. Most of them focus on a predictable set of variables that include some variation in setting employee performance goals, evaluating performance, and providing feedback (Gruman and Saks, 2011). Baird et al (2020) address the issue of the impact of employee empowerment on defined dimensions of the quality of the performance appraisal system, such as trust, clarity, communication, and fairness. To increase employee performance, Humato and Melinda (2021) recommend going the way of increasing employee motivation, meeting their expectations, improving their knowledge and skills, creating a pleasant work environment, increasing the role and support of managers in overcoming work problems, and rewarding their achievements and using punishment for employees who do not perform their tasks. The importance of transformational leadership concerning employee performance is emphasized by Erlina (2020) and Dwivedi et al. (2020) The biggest challenge facing leaders in today's organizations is how to build a culture of employee engagement and leverage as a driving force for performance (Governer and Bussin, 2020).

The results of employee performance evaluation are standardly used in business practice for several personnel activities. Remuneration is naturally one of the most important and expected activities of employees. The changes brought about by the COVID-19 pandemic also resulted in a shift in employee expectations regarding evaluation and subsequent remuneration. During COVID-19, many organizations attempt to design and redesign their remuneration system to meet the real needs of employees (Aldoghan et al., 2021).

The COVID-19 pandemic has demonstrably caused significant staff turnover, including managers. This also raises the question of how to evaluate and subsequently reward employees who leave the organization and later seek their readmission to the same organization. Arnold et al. (2020) discuss the issue of so-called boomerang employees, questioning whether the recruitment and retention of these workers are beneficial to the company.

In this context, the research team was looking for an answer to the question: Has the corona crisis been reflected in the method of evaluating the performance of employees in companies in the Czech Republic? Specifically, they sought answers to the following questions:

- Has the corona crisis changed employee ratings? If so, what change is it?

- How do companies now carry out employee performance appraisals and with what frequency?

- In what personnel activities are the results of employee performance evaluation used?

\section{Methodology}

The article is based on primary sources obtained by research in the spring of 2021 on the state of personnel work during the first year of the COVID-19 pandemic in the Czech Republic in 2020. The respondents were businesses of all sizes operating in all sectors of the national economy in all regions of the Czech Republic. Questionnaires were sent in electronic form to competent managers willing to cooperate. The main goal of the research survey was to obtain data on the attitudes of business entities operating in the Czech Republic to personnel work in their organization. 390 duly completed questionnaires were collected. This article presents the attitude of these entities with a focus on evaluating the performance of employees. 
The questionnaire survey's information support did not permit the submission of an incomplete questionnaire. The obtained data were automatically rewritten into a data matrix in MS Excel, which was used together with SPSS for statistical analyses. The total internal reliability was measured using Cronbach's alpha which had a value of 0.876 , while partial analyzes internal reliability of data ranged around values 0.81 which satisfies the condition for further data analysis (Nunnally, 1978).

Descriptive statistics tools were used for the basic characteristics of the obtained data. Adequate tools of inductive statistics, the chi-square test, were used to test the established hypotheses. Testing was performed at a significance level of 0.05 .

\section{Results and Discussions}

It can be assumed that the global change caused by the global pandemic COVID-19 will bring a number of changes to the implementation of personnel processes. The survey showed that the original procedures in the evaluation of employee performance are still practiced by $68.21 \%$ of companies, while changes in the evaluation affected by the pandemic situation are reported by $31.79 \%$ of employers. This was mainly a change in the periodicity of the evaluation (69.35\%). The second most significant change $(58.87 \%)$ was the introduction of new weights and evaluation criteria. Other ways to change employee performance appraisals are listed in the following table.

Table 1. The way of changing the evaluation of employee performance.

\begin{tabular}{|c|c|}
\hline Implemented changes & \\
\hline Introduction another evaluation system & $41.94 \%$ \\
\hline Introduction of evaluation scales for different situations & $22.58 \%$ \\
\hline Introduction of new weights and criteria & $58.87 \%$ \\
\hline Change in the periodicity of evaluation & $69.35 \%$ \\
\hline
\end{tabular}

Note: Respondents had the option of choosing multiple answers.

Source: Own research

The research also found out whether the implemented change in the method of evaluating the performance of employees depends on the size of the company. Here it can be stated that no statistically significant dependence was found $(p$-value $=0.087$ ).

Upon closer examination of changes in the periodicity of evaluation, it was found that before the crisis, the annual evaluation of employee performance dominated $(31.63 \%)$. However, during the crisis, this was an evaluation carried out irregularly $(32.31 \%)$. Nevertheless, even during the crisis, as many as $24.62 \%$ of companies maintained their annual review frequency. Further results concerning the periodicity of employee performance appraisal are provided in Table 2. It shows a shortening of the appraisal interval towards monthly intervals or irregular appraisals. The statistical test confirmed that the shift is statistically significant $(\mathrm{p}$-value $=0.031)$. From the obtained data it is not possible to unambiguously determine whether the stated periodicity, resp. irregularity is optimal for the operation of the company and is sufficient motivation for employees to maintain or increase their performance.

Table 2. Periodicity of employee evaluation.

\begin{tabular}{|c|c|c|}
\hline Periodicity of employee evaluation & Before COVID-19 & During 2020 \\
\hline Once a year & $31.63 \%$ & $24.62 \%$ \\
\hline Semi-annually & $11.90 \%$ & $8.46 \%$ \\
\hline Quarterly & $13.95 \%$ & $12.56 \%$ \\
\hline Monthly & $18.37 \%$ & $18.97 \%$ \\
\hline Otherwise regularly & $2.38 \%$ & $3.08 \%$ \\
\hline
\end{tabular}




\begin{tabular}{|c|c|c|}
\hline Irregularly & $21.77 \%$ & $32.31 \%$ \\
\hline Total & $100.00 \%$ & $100.00 \%$ \\
\hline
\end{tabular}

Source: Own research

The evaluation of the method of carrying out the examined personnel activities yielded an interesting finding, as companies that use an informal style of evaluation continue to predominate (originally $42.52 \%$, now $45.64 \%$ of companies). In both periods, about $31 \%$ of companies report a combination of formal and informal methods of evaluation, and $23.59 \%$ of companies now use an exclusively formal method of evaluation ( $26.87 \%$ before the crisis). These minor differences cannot be considered statistically significant ( $\mathrm{p}$-value $=0.579$ ), i.e. the first year of the pandemic did not affect the style of employee performance appraisal. The evaluation style may not have negative effects on the perception of the evaluation result by employees.

As expected, the connection between the implemented evaluation style and the size of the company was proved, when there is a very strong statistical dependence ( $p$-value $=1.87 \cdot 10^{-}$ 28 ). Informal style predominates in micro-enterprises ( $74 \%$ of them), it still predominates in the group of small enterprises, but the strength of dominance is no longer so high (in half of the enterprises). As the size of companies grows, the formal style of employee performance appraisal significantly dominates.

Table 3. Personnel activities using employee evaluation.

\begin{tabular}{|c|c|c|c|}
\hline & Before COVID-19 & During 2020 & p-value \\
\hline Personnel planning & $21.09 \%$ & $27.44 \%$ & 0.057 \\
\hline Job analysis & $14.63 \%$ & $15.13 \%$ & 0.855 \\
\hline Education and development of employees & $38.78 \%$ & $35.64 \%$ & 0.401 \\
\hline Remuneration & $86.73 \%$ & $79.23 \%$ & 0.011 \\
\hline Placement of employees & $16.67 \%$ & $19.49 \%$ & 0.345 \\
\hline Other & $1.02 \%$ & $1.03 \%$ & $* * *$ \\
\hline
\end{tabular}

Note: Respondents had the option of choosing multiple answers. ${ }^{* * *}$ test prerequisites were not met Source: Own research

It is argued that changes in employee evaluation will have serious consequences for most personnel processes, and therefore it is necessary to incorporate changes in evaluation into other personnel activities in companies. The investigation revealed that no significant effects of the pandemic on the use of employee performance appraisals were recorded. Most companies still use the results of employee performance appraisals primarily as a basis for remuneration $(79.23 \%)$. The second place in the use was won by the education and development of employees (35.64\%), which testifies to a good strategy of the company. Subsequently, almost a third of the results of performance evaluation are used by companies for personnel planning. This creates an objective basis for evaluating the performance and progress of positively evaluated employees. Furthermore, the evaluation results are used in the area of staff placement (19.49\%) and the process of job analysis (15.13\%). Only $1.03 \%$ is used for unspecified partial personnel activities. The use of employee performance appraisal before the pandemic and during its first year in companies in the Czech Republic is shown in Table 3 . The last column also shows the result of testing the difference in use before the crisis and in its first year. It is evident that a statistically significant difference was recorded only for remuneration.

\section{Conclusion}

COVID-19 has affected the whole world. From the standpoint of business management, it was not easy to manage the unpredictable development of the situation, which was heavily 
influenced by the often-chaotic decisions of the heads of state, including politics in the Czech Republic. Often announced lockdowns meant a significant reduction in production for companies until it was stopped. The COVID-19 pandemic therefore naturally affected the performance of employees in companies in the Czech Republic. The authors of the article were interested in the extent to which the evaluation of the performance of employees in these companies has therefore changed.

Based on the primary research, it has been discovered that the COVID-19 pandemic is reflected in the evaluation of employee performance in companies in the Czech Republic, where a change in the rating is reported by almost $1 / 3$ of companies. These changes consist mainly in changing the periodicity of evaluation and in introducing new weights and criteria in the system of employee performance evaluation. These changes were implemented regardless of the size of the company.

Before the COVID-19 crisis, the annual evaluation of employee performance dominated $(31.63 \%)$. During the crisis, $24.62 \%$ of companies continued to practice this periodicity. The irregular evaluation of employee performance, which is used by $32.31 \%$ during the crisis, has become increasingly important. Nevertheless, even during the crisis, as many as $24.62 \%$ of companies maintained their annual review frequency. The change in periodicity towards shorter intervals or irregular evaluation is statistically significant.

On the contrary, no fundamental changes in the style of conducting employee performance appraisals have been found. More than $40 \%$ of companies approach evaluation informally, about $31 \%$ of companies combine a formal style of evaluation with informal. The informal style of evaluation is typical of small businesses. As the size of companies grows, the formal style of evaluating employee performance significantly dominates.

The results of employee performance evaluation are used by companies in a number of different personnel activities. Even before the COVID-19-caused crisis, and even during its first year, its use for employee remuneration dominates, when it is statistically significantly more used during the crisis than before the crisis. Furthermore, the evaluation is used for further education and development of employees (for more than $1 / 3$ of companies), almost $1 / 3$ of companies use the results of performance evaluation for personnel planning. Apart from remuneration, no significant differences have been found between the periods examined in any personnel activity.

The results presented in the article relate only to the first year of the COVID-19 pandemic. However, this pandemic is still ongoing and its effects will continue. Business management should perceive this fact as a challenge and prepare for an adequate response to their manifestations so that negative impacts are maximally eliminated and opportunities are maximized.

\section{Acknowledgments}

This work was supported by the Silesian University in Opava, by the Student Grant System SGS/14/2021 "Smart Performance Dashboards in Business Practice".

\section{References}

1. Mihus, I., Laptev, S., Parashchenko, L., Koval, Y., Odarchyk, K., \& Panchenko, O. (2021). The impact of the covid-19 pandemic on the loyalty of employees. AD ALTA: Journal of Interdisciplinary Research, 1(11), 38-41.

2. Lee, T. C., Yao-Ping Peng, M., Wang, L., Hung, H. K., \& Jong, D. (2021). Factors influencing employees' subjective wellbeing and job performance during the COVID- 
19 global pandemic: The perspective of social cognitive career theory. Frontiers in Psychology, 12(455).

3. Wei, X., Li, L., \& Zhang, F. (2021). The impact of the COVID-19 pandemic on socioeconomic and sustainability. Environmental Science and Pollution Research, 1-10.

4. Stofkova, Z., \& Sukalova, V. (2020). Sustainable development of human resources in globalization period. Sustainability, 12(18), 7681.

5. Aldoghan, M., Elrayah, M., \& Debla, F. (2021). The job quality dimensions and employees performance during covid-19: A case study of the saudi's female employees. Polish Journal of Management Studies, 23(2).

6. Govender, M., \& Bussin, M. H. (2020). Performance management and employee engagement: A South African perspective. SA Journal of Human Resource Management, 18(1), 1-19.

7. Aşkun, V., ÇİZEL, R., \& Ajanovic, E. (2021). Comparative analysis of factors affecting employee performance according to job performance measurement method: The case of performing artists. Ege Academic Review, 21(1), 29-45.

8. Humato, S., \& Melinda, T. (2021). Improving employees' performance in citra mandiri mobil. KnE Social Sciences, 34-45.

9. Erlina, R. (2020). The effects of leadership and employee performance on innovation performance among Indonesian SMEs. Polish Journal of Management Studies, 21.

10. Gruman, J. A., \& Saks, A. M. (2011). Performance management and employee engagement. Human Resource Management Review, 21(2), 123-136.

11. Dwivedi, P., Chaturvedi, V., \& Vashist, J. K. (2020). Transformational leadership and employee efficiency: knowledge sharing as mediator. Benchmarking: An International Journal.

12. Arnold, J. D., Van Iddekinge, C. H., Campion, M. C., Bauer, T. N., \& Campion, M. A. (2020). Welcome back? Job performance and turnover of boomerang employees compared to internal and external hires. Journal of Management, 0149206320936335.

13. Kucharčíková, A., Mičiak, M., \& Hitka, M. (2018). Evaluating the effectiveness of investment in human capital in e-business enterprise in the context of sustainability. Sustainability, 10(9), 3211.

14. Baird, K., Tung, A., \& Su, S. (2020). Employee empowerment, performance appraisal quality and performance. Journal of Management Control, 31(4), 451-474.

15. Agarwal, P., \& Farndale, E. (2017). High-performance work systems and creativity implementation: the role of psychological capital and psychological safety. Human Resource Management Journal, 27(3), 440-458.

16. Munandar, A. (2015). Participatory performance measurment or self-assessment: amerlioration employee job satisfaction. Research Journal of Finance and Accounting, 6(14), 67-71.

17. Purnaya, I. G. K., S. E., S. H., M. Si. (2016). Manajemen Sumber Daya Manusia. Jakarta: Penerbit Andi.

18. Nunnally (1978) Psychometric Theory. New York: McGraw-Hill.

19. Tomcikova, L., \& Coculova, J. (2020). Leading and education of talented employees as one of the major impacts of globalization on human resources management. In SHS Web of Conferences. EDP Sciences, 74, 04029. 